\title{
Hands on Alemtuzumab-experience from clinical practice: whom and how to treat
}

\author{
Lina Hassoun, Judith Eisele, Katja Thomas and Tjalf Ziemssen*
}

\begin{abstract}
Alemtuzumab is a monoclonal antibody, which was recently approved for the treatment of active relapsing remitting multiple sclerosis. Its main mechanism of action is based on targeting CD52, an antigen of unknown function which is found on B and T lymphocytes, leading to depletion followed by repopulation of these cells. The high efficacy of Alemtuzumab in controlling relapsing remitting MS has been shown in several clinical trials. This new therapy approach is associated with a specific side effects profile requiring regular longterm monitoring. The most important side effects are infusion-associated reactions, a slight increase of infections as well as autoimmune events in almost one third of treated patients.

Based on two years of clinical experience in Germany, this review covers the first steps with the careful patient selection to be treated with Alemtuzumab over the preparation steps and the infusion courses up to the longterm monitoring after Alemtuzumab treatment.
\end{abstract}

\section{Background}

In September 2013, Alemtuzumab was approved in Europe as an additional therapeutic option for active relapsing-remitting Multiple Sclerosis (RRMS). Since its synthesis in the early eighties as the first humanized monoclonal antibody, Alemtuzumab therapeutic potentials were explored for many diseases (eg. Graft versus host disease, transplantation, vasculitis, rheumatoid arthritis, immunologically mediated cytopenia) $[1,2]$; it is the first depleting monoclonal antibody which was licensed for the treatment of RRMS. The mechanism of Alemtuzumab differs from immunmodulating and other immunosuppressive treatments in its fundamental approach, which consists of at least two courses of lymphocyte depletion followed by cellular repopulation. The reconstitution of lymphocytes is thought to be of particular importance not only for the beneficial clinical effects, but also for the long-term side effects [3]. Alemtuzumab is introducing a new therapeutic concept of an inductionlike treatment strategy, but without the need of a maintenance treatment in the follow up in most of the treated patients. Such concepts are till now not well established in our clinical practice. Furthermore, other highly efficacious

* Correspondence: Tjalf.Ziemssen@uniklinikum-dresden.de MS Center Dresden, Center of Clinical Neuroscience, Department of Neurology, University Hospital Carl Gustav Carus, Dresden University of Technology, Fetscherstr. 74, 01307 Dresden, Germany treatment options such as Natalizumab and Fingolimod are available. No clinical trials have directly compared Alemtuzumab with these medications making the clinical decision not straight forward.

Although the role of Alemtuzumab in RRMS was investigated in three active-controlled clinical studies [4-6], using it in clinical practice can be quite challenging as several questions are still to be answered: how to define patients who will most likely profit from Alemtuzumab? Where does Alemtuzumab stand in MS treatment scenario? And then if Alemtuzumab is to be given, how should we switch patients from other specific MS treatments to Alemtuzumab? What other MS medications could be given following Alemtuzumab? How could the infusion management be optimized? Which side effects can be expected and how should they be handled? What is the most applicable monitoring strategy in clinical practice?

The aim of this review is to summarize our experience with Alemtuzumab in clinical practice of the last two years following a structured approach starting with treatment selection followed by preparation and infusion management up to the longterm monitoring.

\section{The innovative treatment concept of alemtuzumab}

Alemtuzumab is a monoclonal antibody that selectively binds to CD52, which is a surface glycoprotein molecule 
of unknown function [7]. It is expressed on the surface of $\mathrm{T}$ - and B-cells and other cell populations but not on the hematological precursors [8]. Alemtuzumab infusion results in rapid depletion of the CD52 positive cells [9], leading to lymphopenia, which lasts for several years [10]. While B-cells recover relatively quickly within a range of 3-8 months, the repopulation of $\mathrm{T}$ cells occurs more slowly, as it needs up to 3 years and in another study up to 60 months for CD4+ and 30 months for CD8+ $\mathrm{T}$ cells in average $[11,12]$. The experimental data using humanized CD52 mice have shown, that the depletion of lymphocytes upon anti-CD52 treatment was predominant in peripheral circulation, while the number of those cells was clearly less affected in spleen, thymus, bone marrow and lymph nodes [13, 14]. This may represent an explanation for the unexpected low rate of infections in patients receiving Alemtuzumab. As mentioned before, the depletion of CD52-positive cell is followed by a recovery phase that can vary between treated patients. However, it was shown that different repopulation kinetics among patients was not able to predict the risk of MS reactivation [14-16].

This process is considered as part of the reprogramming of the dysregulated immune system. Some authors suggest that the observed prolonged effect of Alemtuzumab lies in the slow reconstitution of $\mathrm{T}$ lymphocytes after the initial depletion, and not in the depletion itself [3].

The radical approach of Alemtuzumab which leads to its prolonged therapeutical effect is actually also associated with the well-described side effects. In addition to the infusion-associated reactions (IAR), which will be described in more details later, the increased incidence of antibodymediated autoimmune diseases upon Alemtuzumab therapy is remarkable [17]. Taking into consideration the previously described mechanism of immune cells depletion and the potential side effects, the need arises to find appropriate criteria that are useful for patient selection.

No biomarker to detect predisposition for secondary autoimmunity has been found yet. IL-21 was previously described as a promising candidate but these results could not be reproduced in another following study, which was attributed to the use of different kits $[18,19]$.

\section{Different treatment strategies}

Alemtuzumab therapy consists of two courses with 12 months in between. In spite of this non-frequent intermittent administration of the medication, this approach guarantees a long-term stabilization of the disease activity and to achieve the therapeutic effect, keeping in mind that Alemtuzumab infusions should take place under close monitoring. Until now, all available highly-efficacious therapies as Natalizumab and Fingolimod follow a continuous treatment strategy. After stopping these drugs, disease activity is returning or even overshooting as it has been described for Natalizumab [20, 21] and also even in fewer cases for fingolimod [22-25]. On the other side, treatment switches are easier to perform if a more or less reversible treatment as Fingolimod or Natalizumab is applied. The disadvantage is that the use of other treatment approaches after Alemtuzumab is more complicated due to the effects of irreversible depletion and repopulation, on the other side patient is practically off treatment after the second Alemtuzumab infusion. The rapid onset of Alemtuzumab treatment effects can be explained by depletion of both cells of the acquired and innate immune system, including the impairment in activation as well as cytokine release [9].

Comparing side effects, Alemtuzumab has specific windows where side effects are increased specifically (IARs during infusion, infections directly after infusion, secondary autommunity with a maximum in the third year) $[26,27]$ which is different to risk of adverse events of eg. Natalizumab presenting an increased PML risk after a certain treatment duration [28]. In the field of MS treatment, we have for the first time different treatment strategies with different efficacy and risk profiles during the treatment duration which should be considered before treatment is selected (Fig. 1). Alemtuzumab presents with characteristics of induction treatment although strategy is not correctly defined by the term induction treatment as in the most cases no maintenance treatment is necessary at least for the 5 year window after treatment start [29].

\section{Patient selection: who is the right patient for Alemtuzumab?}

According to the European Medicines Agency (EMA), Alemtuzumab is approved for the treatment of patients with active RRMS [30], whereas disease activity is defined by clinical and/or imaging criteria. According to the criteria for assessment of MS activity proposed by Lublin and colleagues [31], a patient with RRMS would be considered as having an active course if a clinical relapse took place or the brain MRI showed new Gadolinium-enhancing and/or the increase in size or number of T2 lesions. MRI monitoring should be done in regular annual intervals [32]. In the clinical trials, the disease duration was limited to 5 years in treatment naïve and to 10 years in pretreated patients $[4,6]$ probably because Alemtuzumab was not able to cause improvement in SPMS patients in a small pivotal study [11]. So in our opinion, the benefit of the patients regarding Alemtuzumab treatment is optimal if significant inflammatory signs are present clinically and by MRI. So Alemtuzumab is not indicated for patients who do not show any disease activity, and it is also not considered as a standard alternative for patients who are stable on current therapy.

It should be emphasized that for MS patients with high disease activity, highly efficacious therapy options 


\section{Continuous MS treatments (eg. Natalizumab)}
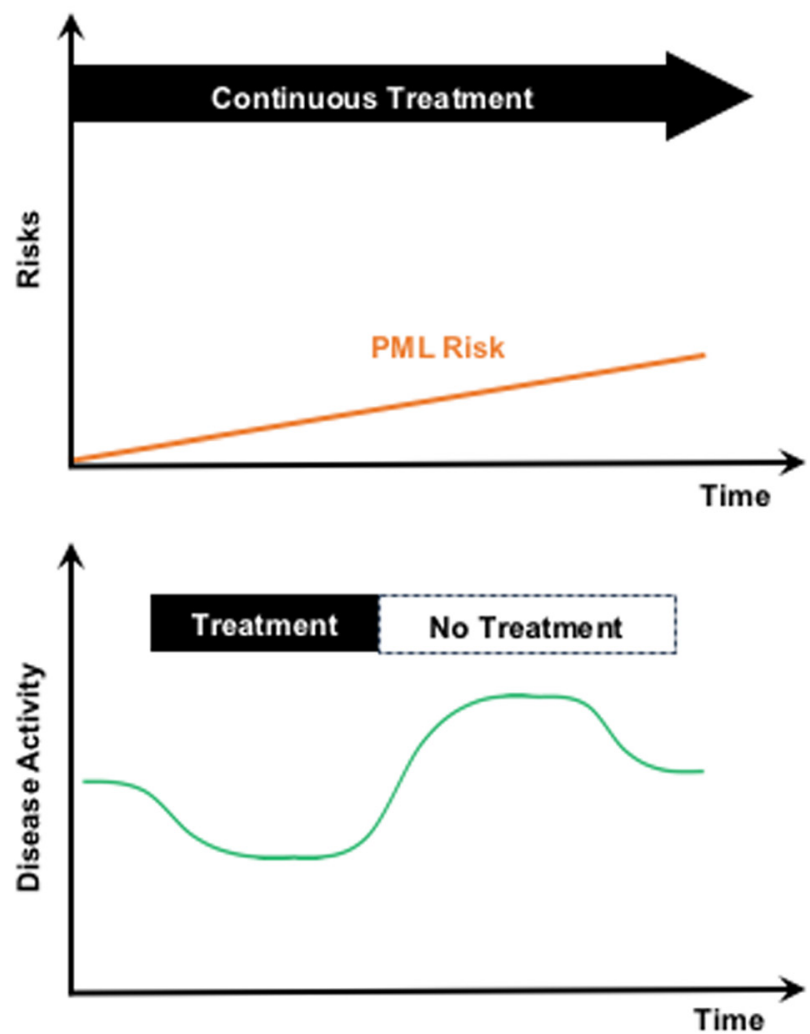

Course-based MS treatments (eg. Alemtuzumab)

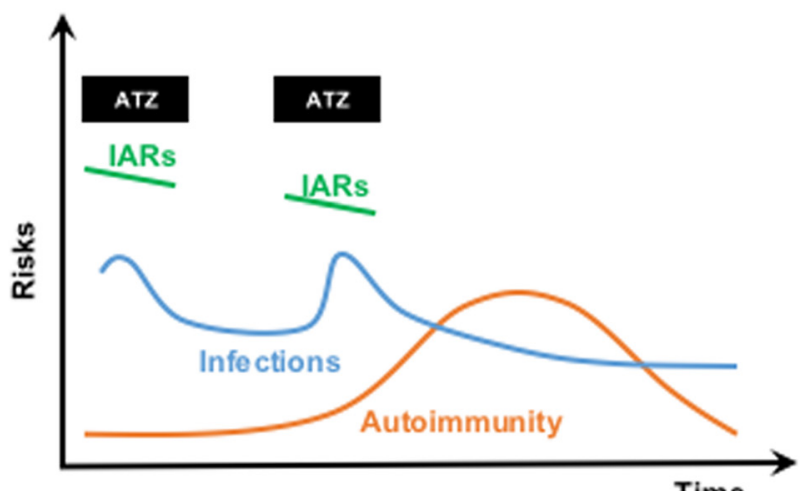

Time

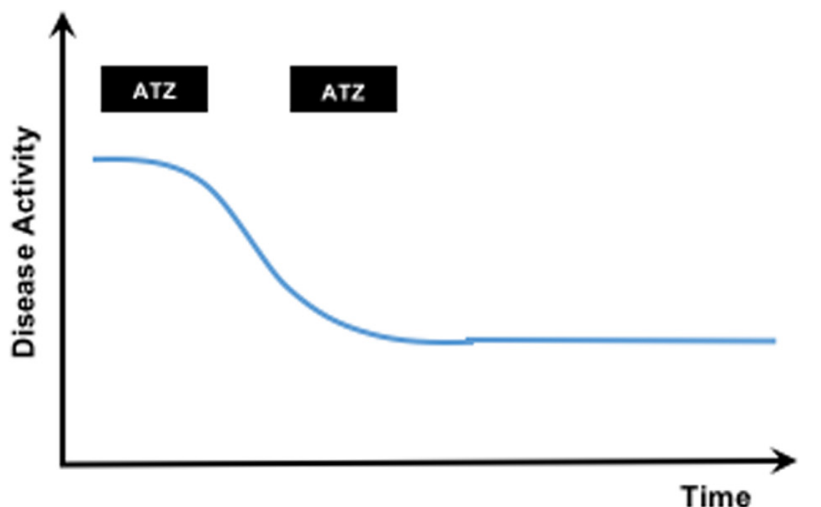

Time

Fig. 1 Comparison of different highly efficacious RRMS therapy strategies Alemtuzumab (right), and Natalizumab (left). The upper diagrams show the adverse effects, which happen usually within specific time windows, the lower diagrams the clinical efficacy

such as Alemtuzumab should be used early within a "window of opportunity" [33]. That implies that the optimal timing would be in the presence of significant clinical and MRI inflammatory activity without significant disability [34]. Therapeutical efficacy of Alemtuzumab is most prominent in early stages of disease by reducing inflammatory activity to counteract the development and accumulation of disability $[11,35]$. Patients presenting with an EDSS value up to 3-4 still potentially have predominant inflammatory processes, while irreversible damage is increasingly assumed to be associated with higher EDSS values [36]. Accordingly, Alemtuzumab is most appropriately to be used before an EDSS score of 4 is reached. This should not be interpreted that patients with higher EDSS scores can not benefit from treatment with Alemtuzumab, as the indication should be considered based on clinical and/or radiological disease activity Actually in some patients Alemtuzumab is used as "last option" treatment as many treatments before have failed. The efficacy of Alemtuzumab as last option treatment strategy has to be investigated by defined cohort or real world studies [37, 38].

In addition to the disease activity as a determining factor in the therapeutic decision, other factors, such as patient personality and cognitive skills, should be taken into consideration. Because of necessary longterm monitoring patient's discipline is demanded, as Alemtuzumab treatment is potentially associated with severe adverse effects which have to be identified early [39].

Keeping in mind that different forms of MS are mediated by different pathological processes, possibly implicating different therapeutical approaches, the diagnosis and classification of MS should be definitely confirmed. Neuromyelitis optica (NMO) which was long been considered as a special form of MS, is associated with different etiology. Alemtuzumab is not considered as a first line treatment option in this disease, as several case reports showed a worsening of NMO under Alemtuzumab treatment [40-42]. 
As no previous studies have yet compared the efficacy of Alemtuzumab directly with other highly active therapies, such as Natalizumab or Fingolimod, the clinical decision to choose one of the above mentioned medications is largely based on other factors. That would include on top of the list the potential side effects of each drug versus the expected benefit. Additionally the relative and absolute contraindications should be carefully assessed to choose the most suitable drug. For example, patients with positive anti-JCV status represent high-risk group for PML development on longterm Natalizumab treatment [43]. For female patients in child-bearing age, Alemtuzumab can be the choice, but the it should be planned 4 months after the last infusion [44].

There are relative and absolute contraindications for Alemtuzumab treatment, which should be taken into consideration (Table 1).

\section{Patient preparation: pretreatment}

The strategy how to initiate the treatment with Alemtuzumab depends on pretreatment status of the patient (Fig. 2). In treatment-naïve MS patients, an immediate start of Alemtuzumab is possible. Moreover, Alemtuzumab treatment accompanied with high dose steroids can itself even be used as an acute relapse treatment. Direct switching from Interferon-beta or Glatiramer Acetate to Alemtuzumab is also possible without any specific washout period if no relevant laboratory abnormalities (for example lymphocytopenia) are present. In case of Teriflunomide and Dimethylfumarate, it is advised to wait at least one month before Alemtuzumab administration, as it is

Table 1 Absolute and relative contraindications of Alemtuzumab

Absolute contraindication

Hypersensitivity to the active substance, or to any of the excipients.

Severe active infections. Additionally, this drug should not be used in the presence of active chronic or recurrent bacterial or viral infections, such as TB, HCV. HBV or HIV.

Pregnancy or lactation.

Relative contraindication

Blood coagulation disorders such as dysfibrinoginemia, factor IX deficiency, hemophilia, von Willebrandt disease, or anti-coagulation therapy.

Significant infection liability, such as aspiration susceptibility or frequent urinary tract infection.

Malignant diseases in the patient history, which is not curatively treated.

Thrombocytopenia.

Negative Varicella-zoster lgG status

Severe liver or kidney insufficiency

Children under 18 years of age required that the levels of lymphocytes are within normal range $(>1.5 \mathrm{GPt} / \mathrm{l})$. It is also recommended to accelerate Teriflunomide elimination by Cholestyramine application and determine its blood concentration before the Alemtuzumab start. Patients stopping Fingolimod should have recovered to physiological absolute lymphocyte counts as well which is an important pharmacodynamics parameter considering the mechanism of action of Fingolimod [45]. In patients switching from Fingolimod, we are not as strict with a recovered absolute lymphocyte count $(>1.0 \mathrm{GPt} / \mathrm{l})$ as with Dimethylfumarate $(>1.5 \mathrm{GPt} / \mathrm{l})$ as Fingolimod is only affecting lymphocyte redistribution between lymphoid tissues and blood.

Prior therapy with Natalizumab represents a special situation as the switching protocol depends on the actual PML risk which is closely linked to the JCV status and treatment duration [28]. The challenge is to find a way between returning disease activity after Natalizumab and PML risk. Because of the irreversible and acutely immunosppressive mechanism of action of Alemtuzumab, a carryover PML after natalizumab treatment which has been described occurring even up to 6 months after Natalizumab cessation has to be excluded before treatment start $[46,47]$. So if there is only a low PML risk which means treatment duration with Natalizumab less than 2 years and/or negative anti-JCV antibodies, a washout period between two and three months is considered sufficient until pharmacodynamic effects of Natalizumab have disappeared. MRI and possibly CSF analysis should be performed as part of the work up as described later. For patients with higher PML risk (JCV antibody positive and treatment duration $>2$ years) we recommend a stepwise approach. 3 months after last infusion first MRI should be performed to exclude PML and monitor return of disease activity. If no MRI activity is present, follow up MRI will be performed 4 weeks later which will be repeated until 6 months. If there is MRI activity (or clinical activity) present, CSF analysis with JCV DNA and cell count should be performed before Alemtuzumab is started. This procedure has been applied many times in our clinical practice and can avoid return of clinical activity and makes PML much more unlikely. This means that a strict 6 months washout period cannot be applied in all PML high risk patients on Natalizumab. It is crucial to implement an individual approach for the switch of natalizumab to Alemtuzumab. As irreversible, cell depleting therapy, a carry over of a Natalizumab-associated PML has to be avoided in potential Alemtuzumab patients. In our hands, identifying patients with MRI activity was mostly sufficient to avoid clinical rebound activity as Alemtuzumab demonstrates a rapid onset of action. After immunosuppressive therapies, such as Azathioprine, Cyclosporine A, Mitoxantrone or Cyclophosphamide, which are rarely used nowadays, wash-out period of 3-6 months is necessary in 


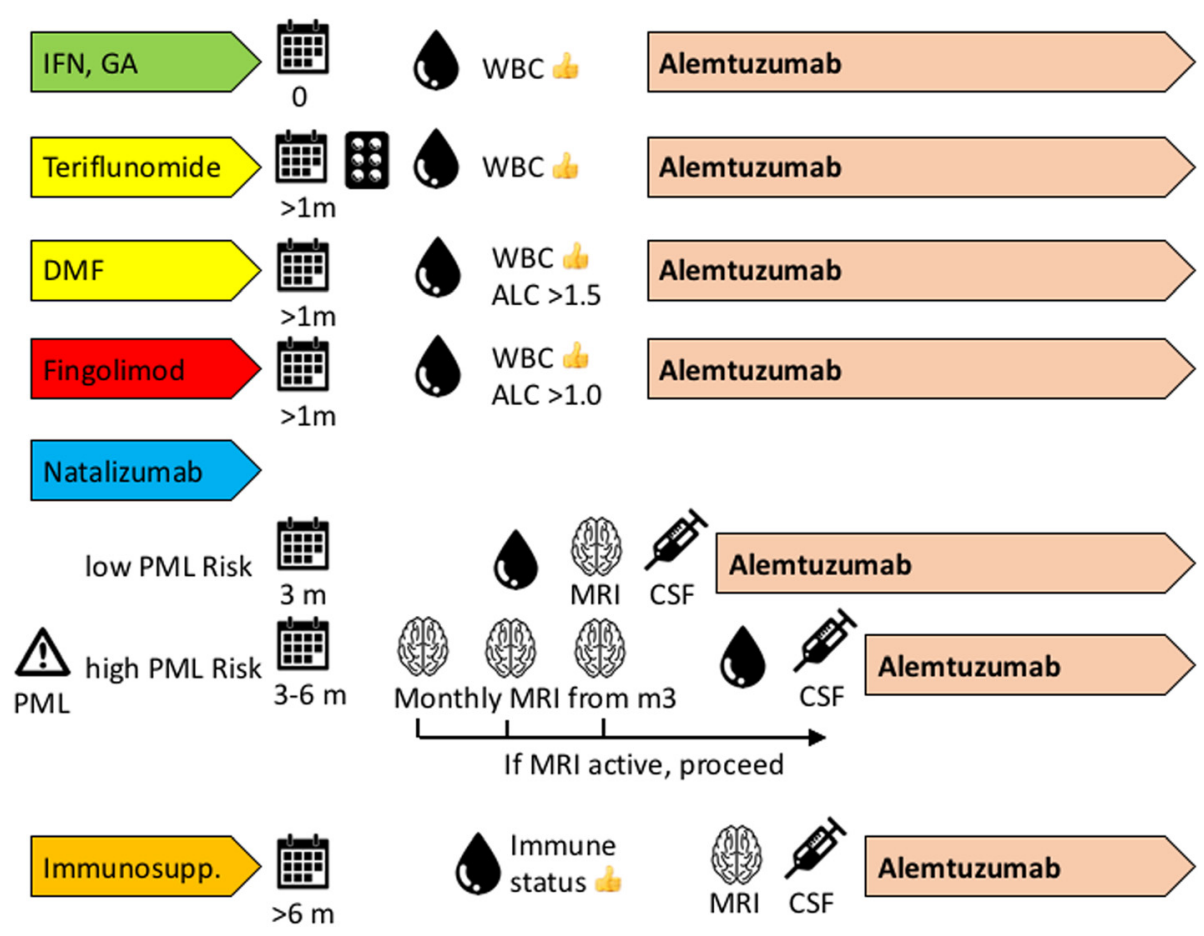

Fig. 2 Recommended protocols for switching to Alemtuzumab, regarding different pretreatments. Special attention should be paid for patients who were previously treated with natalizumab, two different protocols are suggested depending on the individual PML risk

addition to physiological white blood cell counts. Nevertheless patients after immunosuppressive pretreatment are not the ideal patients although case reports have reported beneficial effects [37].

In general, it should be kept in mind that these recommendations are general. In everyday clinical practice we are confronted with special individual patient cases that may require deviation from the general recommendations. These adjustments are justified depending on the individual disease activity and progression, and it is advisable to document the reason for the different approach appropriately [48].

\section{Patient preparation: preparatory steps}

Taking into consideration the well-known side-effects and contraindications of Alemtuzumab, a detailed patient history and physical examination should be performed to exclude possible contraindications. Effective treatment should be given in case of acute infections. It is required to wait until the infection is cured before going on with the Alemtuzumab infusion. On the other hand, chronic Infections such HBV, HCV, TBC and syphilis (except HIV) do not represent absolute contraindications, but their presence demands additional carefulness. An active infection should be excluded. In case of a positive quantiferon test, active TBC has to be excluded by chest X-ray and prophylactic treatment with Isoniacid for at least half a year has to be started before Alemtuzumab treatment can begin 6-8 weeks later
[49]. Neoplasms, which are considered as relative contraindication, should be cured before initiating Alemtuzumab treatment. Recommended lab tests before starting treatment with Alemtuzumab are described in Table 2. This workup should be done before every Alemtuzumab infusion later on.

MRI of the complete neuroaxis (not older than three months) should be performed as documentation for baseline status before Alemtuzumab start. All the abovementioned tests should be accomplished and managed before the first treatment course; and these safety investigations should be repeated prior to the commencement of

Table 2 Recommended lab testing before Alemtuzumab treatment/retreatment

Differential blood count, and optionally an immune status depending on the pretreatment and on the number of lymphocytes

Liver panel including SGOT, SGPT, GGT, bilirubin

Kidney panel including Creatinine, GFR

Thyroid panel including TSH, T3, T4

Infection status including Syphilis, VZV, HIV, hepatitis serology, TB test (eg. Quantiferon test)

Coagulation panel including INR, PTT

Urine panel including quantitative urinalysis by sediment microscopic analysis

HPV screening and pregnancy test in women

Infection screening panel including CRP, BSG 
the second treatment course. There are no specific requirements regarding lymphocyte or leukocyte cell counts which have to be reached before second Alemtuzumab course.

Women with childbearing potential should be informed to use an effective contraception during treatment phase and four months thereafter.

Especially for patients who have a history of neither chicken pox infection nor of previous vaccination against Varicella-Zoster virus, it is obligatory to measure its antibodies level before initiating Alemtuzumab treatment. We recommend VZV testing in all patients before Alemtuzumab application. For those who are VZV antibody negative the vaccination should be given, followed by measuring the VZV antibody titer four to six weeks after VZV vaccination. As vaccinations may be complication by the depleting-repleting mechanism of action vaccination status should be checked and necessary vaccinations should be performed before first Alemtuzumab application.

Before first Alemtuzumab treatment, patients should be informed about potential side effects and the need for regular monitoring which is mandatory for a beneficial risk-beneftit ratio of Alemtuzumab.

\section{Alemtuzumab infusion management}

Treatment with Alemtuzumab consists of at least two courses of infusion therapy with twelve months in between. During the first course ("the induction course") the monoclonal antibody is intravenously infused over five consecutive days with the recommended dose of $12 \mathrm{mg} /$ day. Out of practical reasons it is useful to start the treatment course on Monday to avoid infusions during weekends. One year later, Alemtuzumab is infused in a second course of treatment ("the maintenance course") over three consecutive days. Between the two treatment courses no immunomodulatory treatment should be applied. Shortening the interval between these two courses is not recommended as there is no experience. To reduce the infusion-associated reactions (IAR), a specific schedule of infusion should be applied (Table 3).

The day before Alemtuzumab infusion, $\mathrm{H} 1$ and $\mathrm{H} 2$ blockade should be initiated which could be applied beyond the infusion week if necessary [30,50]. An antipyretic, given 30-60 min before infusion, may help to reduce the infusion reaction.

In addition, a short infusion of methylprednisolone $(1 \mathrm{~g})$ is recommended for the first three days of treatment. Cytokine release and lymphocyte activation could account for such infusion-associated reactions [51, 52]. Induction of serum cytokines could be due to crosslinking of NK cells in addition to cell lysis [52]. Pivotal studies not using standardized infusion procedure and methylprednisolone pre-treatment demonstrated higher levels of serum cytokines and significant more IARs after initial alemtuzumab infusions [51]. Pre-and concomitant methylprednisolone treatment incorporated into the standard infusion protocol may attenuate cytokine release syndrome and help reduce infusion-associated reactions to enhance patient tolerance [50]. This protocol is based on the procedure in pivotal studies. However, in deviation from this study experience, the steroid infusion may be adjusted depending on the individual situation and the patient's response. This mean extension over 5 days or potential pretreatment one day before Alemtuzumab infusion which is actually investigated in a clinical trial. If the Alemtuzumab course could not be completed over the consecutive 5 days, if the course has to be interrupted because of eg. acute infection with fever, the remaining Alemtuzumab infusions should be performed as soon as possible in the next weeks. In this case, methylprednisolone should be applied before all remaining Alemtuzumab infusions.

Alemtuzumab infusion should be started after methylprednisolone infusion. Mixing these preparations is not allowed, as this can lead to precipitation of the drug. Alemtuzumab itself is diluted immediately before the infusion in $100 \mathrm{ml}$ of $0.9 \%$ sodium chloride solution or $5 \%$ glucose solution (chemically stable at $2-8{ }^{\circ} \mathrm{C}$ for up to $8 \mathrm{~h}$ ). Other infusions could be applied using the same intravenous port as Alemtuzumab, a paravenous infusion is not critical as Alemtuzumab is a monoclonal antibody and not a chemotherapy. The infusion-associated reactions (IAR) occur in up to $90 \%$ of patients treated with Alemtuzumab [50]. Skin reactions are observed predominantly. With mild symptoms, symptomatic treatment with anti-histamergic treatments or antipyretics/anti-inflammatory treatments and slower infusion rate are usually sufficient. In case of severe reactions such as fever, urticaria, atrial fibrillation, nausea, chest discomfort or hypotension, the infusion should be stopped immediately. Because of these potential acute infusion-associated reactions, anaphylaxis therapy should be kept ready although the reaction to Alemtuzumab is generally not anaphylactic, so that the infusion can be further continued. The observation for two hours after the end of the infusion is necessary. In our hand, monitoring of the patient's temperature seems to be an effective method for early detection of an infusionassociated reaction in everyday practice [30]. It is therefore recommended to monitor and document the body temperature every half hour. Heart rate and blood pressure should also be measured every one hour. In addition to this reaction, reappearance of old neurological deficits, which occurred in the context of past relapses, can also occur, which it is caused by the release of cytokines due to cell depletion in a process similar to Uhthoff effect (Cytokine Uhthoff syndrome) [51]. The highest drug level is reached after the last infusion [53]. However, even if this falls in the next few days, its effect with regard to lymphocyte depletion goes on, so that it is still possible to experience reactions related to cells depletion [9]. 
Table 3 Recommended infusion protocol

\begin{tabular}{|c|c|}
\hline \multirow[t]{4}{*}{ Pre-Infusion } & Concomitant medication: The evening before the 1st Alemtuzumab infusion for all infusion stages, orally: \\
\hline & - H1 blockade eg. Cetirizine 1-0-1 (non-sedating H1 antihistamine) \\
\hline & - H2 blockade eg Ranitidine 300 mg 1-0-1 (H2 receptor antagonist) \\
\hline & - Herpes prophylaxis eg. Aciclovir 200 mg 1-0-1 (for HSVNZV prophylaxis; for at least 4 weeks) \\
\hline \multirow[t]{15}{*}{ Infusion } & 1st year: infusion 5 days (Mon.-Fri.) \\
\hline & 2nd year infusion 3 days (3 consecutive days) \\
\hline & Cardiovascular (BP, heart rate) + Body temperature (1x/30 min) Monitoring \\
\hline & - 1st day of infusion course: Perform pregnancy test in female patients with childbearing potential \\
\hline & - Insertion of peripheral permanent port (can also be used for other medications) \\
\hline & 1. 60 min. before Alemtuzumab infusion: \\
\hline & a) Methylprednisolone $1 \mathrm{~g}$ i.v. as short infusion at the first 3 infusion days \\
\hline & b) Paracetamol 1 g. i.v. as short infusion at all infusion days \\
\hline & $\begin{array}{l}\text { 2. Alemtuzumab } 12 \mathrm{mg} \text { i.v. via infusion pump ( } 12 \mathrm{mg} \text { per day on each of } 5 \text { (or } 3 \text { ) days), is prepared as ready-to- } \\
\text { use solution supply (volume } 112 \mathrm{~mL} \text { ). Storage time of the infusion } 8 \mathrm{~h} \text { after preparation. }\end{array}$ \\
\hline & $\begin{array}{l}\text { - Target infusion period about } 4 \mathrm{~h} \text { (in case of side effects-especially at the start of the infusion-reduction of } \\
\text { the infusion speed) }\end{array}$ \\
\hline & $\begin{array}{l}\text { 3. NaCl infusion } 100 \mathrm{~mL} \text { over } 30 \mathrm{~min} \text { (infusion pump), to flush residual medication out of the infusion line } \\
\text { (tube) }\end{array}$ \\
\hline & Also to note: \\
\hline & - Monitoring until $2 \mathrm{~h}$ after infusion \\
\hline & - Drinking adequate liquids (at least $2 \mathrm{l} / \mathrm{d}$ ) \\
\hline & - Availability of trained physician and medical personnel during the entire period of the infusion \\
\hline \multirow{8}{*}{$\begin{array}{l}\text { Potential acute adverse } \\
\text { events }\end{array}$} & 1. Anaphylaxia/anaphylactic shock (quite rare) \\
\hline & 2. Infusion-associated reactions (IAR): \\
\hline & - Erythema, urticaria, pruritis, (fever, headache, fatigue) \\
\hline & - Intensified neurological symptoms (Uhthoff Phenomenon!) \\
\hline & $\rightarrow$ STOP infusion and inform physician immediately! \\
\hline & $\rightarrow$ Fenistil $1 \mathrm{~A}(4 \mathrm{mg})$ i.v. \\
\hline & $\rightarrow$ In case of insufficient effect $\rightarrow 250 \mathrm{mg}$ prednisolone i.v. \\
\hline & Depending on severity of the IAR, continue infusion, but more slowly. \\
\hline \multirow[t]{4}{*}{ Routine follow-up care } & 1. Aciclovir $200 \mathrm{mg}$ 1-0-1 for 4 weeks from the first day of the infusion \\
\hline & 2. Antihistamine (e.g. cetirizine 1-0-1) for an additional week \\
\hline & 3. Paracetamol standby (if headache or fever appear) \\
\hline & First check-up appointment MS centre 4 weeks after infusion. \\
\hline \multirow{6}{*}{$\begin{array}{l}\text { Procedural measures/follow } \\
\text { up checks }\end{array}$} & - Adequate infection protection including adjusting diet (no cheese from raw milk, raw fish/raw meat) \\
\hline & $\begin{array}{l}\text { - During the infusion course, avoid stomach-irritating foods such as fruit acids, carbonates, sharp or strong- } \\
\text { smelling foods, no sodium glutamate-"bland diet" }\end{array}$ \\
\hline & - If applicable, safe contraception methods for at least 4 months after the infusion course \\
\hline & $\begin{array}{l}\text { - Due to the known potential side effects, the regimen of follow-up check-ups organised and implemented by } \\
\text { the MS centre must be strictly observed }\end{array}$ \\
\hline & $\begin{array}{l}\text { - Patients are instructed to observe a low threshold for making an acute appointment in case of infections. In } \\
\text { this respect, the reduced immune competence and reduced lymphocyte count must be considered, } \\
\text { especially in the first months after infusion, and a complete focus screening must be conducted. }\end{array}$ \\
\hline & $\begin{array}{l}\text { - The patient should be informed of the symptoms of possible side effects (eg. ATP, glomerulonephritis), and } \\
\text { should inform the treating physician of them. An early appointment with the physician should also be made } \\
\text { in case of infection. }\end{array}$ \\
\hline
\end{tabular}




\section{Post-infusion monitoring}

Alemtuzumab treatment is associated with an increased risk for the development of autoimmune diseases, for this reason a regular monitoring is indicated to allow for an early recognition and thereby early treatment of these diseases [10, 17, 19, 54-57]. Most of the autoimmune phenomena have a beneficial prognosis if they are identified early and anti-inflammatory treatment is started early. So monthly check-ups should take place up to 48 months after the last infusion, including a complete differential blood count to detect the development of Alemtuzumabinduced thrombocytopenic purpura (ATP) [58, 59]. In addition, monthly monitoring of serum creatinine levels and urine tests with microscopy for an early detection of possible glomerulonephritis are necessary [59]. Thyroid function test using the TSH value should also be performed every three months. In pregnant patients with special interest in thyroid monitoring monthly TSH testing is recommended $[55,57,60]$.

The monitoring does not need to be performed by the treating neurologist. Good experiences are reported in terms of the cooperation with general practitioners, who can perform or arrange for the check-ups. However, it is essential that the treating neurologist ensures that the control tests are carried out according to previous specifications and the obtained results are evaluated. Treating neurologist has to organize and supervise monitoring after Alemtuzumab treatment. Patients should be clearly informed not to wait for problems to happen, but immediately and regularly communicate with their physician. Modern communication tools as email reminders, smartphone could be nicely implemented in the patient management [61].

\section{Collecting real world data in an alemtuzumab registry}

Although the clinical experience with the agent has substantially increased since market introduction, there are only few reports yet on the long-term use of the drug in the routine of physicians and MS centers [10, 16, 44]. That is why real world data about Alemtuzumab data should be collected as the German non-interventional long-Term study foR obsErvAtion of Treatment with Alemtuzumab (TREAT-MS) which is documenting physician and patient experience in daily clinical practice for six years [62]. Data for this non-interventional study will be collected on a widely unselected patient population eligible for Alemtuzumab treatment. It is expected that compared to the clinical studies, patients with more concomitant diseases and/or more concomitant medications will be documented. Together with the high patient numbers and long follow-up period, a substantial number of patient years will be documented and the option for relevant subgroup analyses provided [48].
For this observational study, a protocol was developed based on the risk management plan for alemtuzumab. By participation in the study, physicians are reminded about the investigations and precautions. The documentation system MSDS3D has been shown to be efficient to guide physicians through the study procedures and to collect the relevant information in clinical practice and for the use in previous non-interventional studies such as PANGAEA [63]. It interactively collects data, but also assists neurologists in the execution of complex processes required for comprehensive management of MS patients (Fig. 3a, b) [64-66].

\section{Infections}

As infections can be facilitated by cellular depletion of the adaptive and innate immune system together and infusionassociated reaction symptoms like fever, headache, and fatigue may mimic infectious signs, routine blood analysis is usually a suitable tool to identify infectious conditions. But laboratory monitoring during infusion therapy is not needed, and it can even be affected by cell depletionrelated artifacts [9]. During the the first infusion week, rapid cellular depletion and impairment of activation of different adaptive and innate immune cell subtypes take place accompanied by marked serum cytokine increases. Nevertheless, these acute Alemtuzumab-mediated effects are assumed to lead to several effects observable by standard blood testing, such as the non-infectious increase in leukocyte count, CRP, and PCT, which are of particular importance in identification and monitoring of infectious conditions. Furthermore, transient elevation of liver enzymes, thrombocytopenia, and TSH modulation are demonstrated. So we recommend clinicians to be aware of clinical symptoms and vital data to initiate supportive analysis rather than standard laboratory testing within the first alemtuzumab treatment week [9].

In general, patients should also be advised to avoid the consumption of raw foods such as raw milk products because of possible contamination with listeria [30]. The ability of Alemtuzumab to deplete dendritic cells as well may explain cases of Listeria meningitis linked to the initial Alemtuzumab infusions $[9,67,68]$. Listeria meningitis infection may be facilitated by immune cell depletion in the adaptive as well as the innate immune system, possibly by an outburst of a pre-existing, clinically silent and CD8+ T cell controlled infection due to cellular depletion and activation blockade. These findings highlight the relevance of certain infections, which could be promoted by the depletion and blockade of innate immune subsets, that clinicians should be aware of within the first days after initial Alemtuzumab infusion.

Patients who have acute or chronic infections should not start with Alemtuzumab therapy. As mentioned above the presence of acute infections under Alemtuzumab therapy 
a

Detail instrument blood count

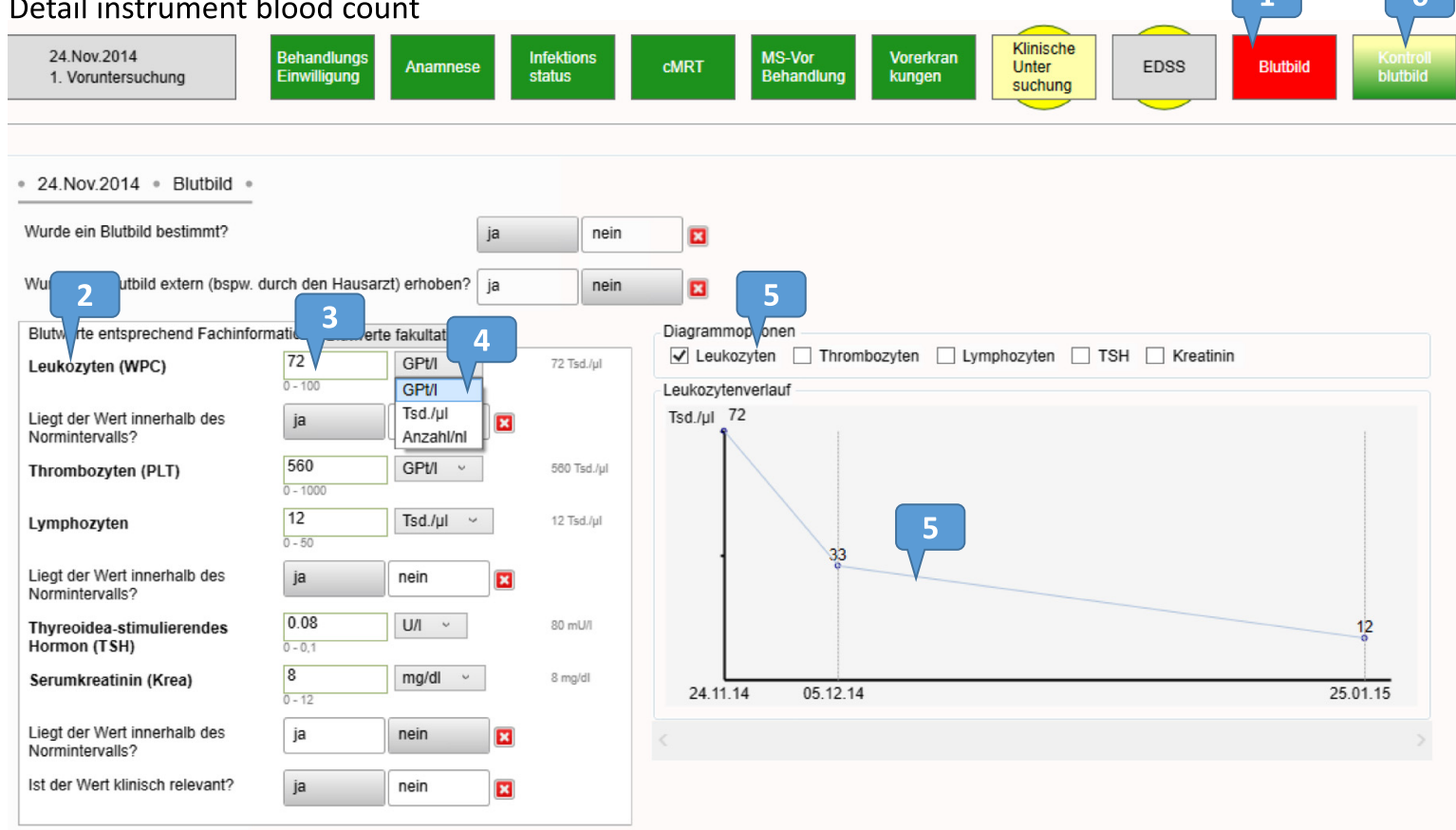

$\mathbf{1}$ - blood count instrument in red state because of clinical significant values $\mathbf{2}$ - blood count parameter $\mathbf{2}$ - blood count parameter value $\mathbf{4}$ - selection of value unit $\mathbf{5}$ - history of selectable blood count parameter $\mathbf{6}$ - automatically added checkup blood count due to significant values in previous blood count

b

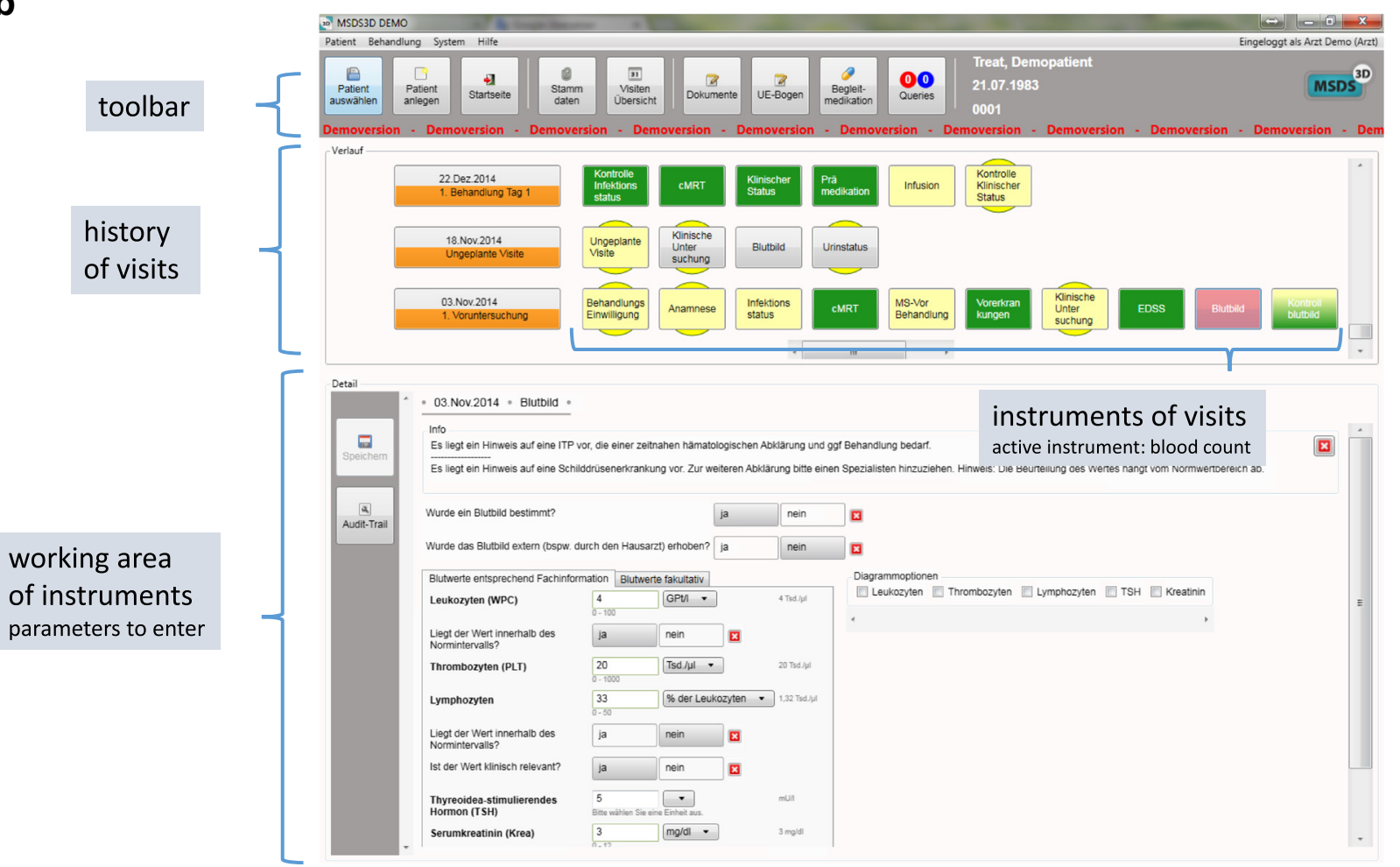

Fig. $3 \mathbf{a}$ a/b The standard protocol for documentation of the different monitoring parameters as displayed on MSDS3D, which enables for monitoring laboratory, clinical, and radiological progression, as well as planning the next step in approaching patients who showed abnormalities 
demands immediate diagnostic and therapeutic procedures. Taking into consideration that human papilloma virus infections (including cervical dysplasia) were described, it is obligatory for female patients to perform an annual HPVscreening with cervical cytology, especially when no former HPV vaccination was given.

Due to the observed increased rate of herpes infections, prophylaxis with acyclovir is recommended [69]. In the phase 3 clinical studies, this prophylactic regimen was introduced not from the beginning on $[4,6,59]$. But the patients receiving $200 \mathrm{mg}$ of acyclovir twice daily or an equivalent for this purpose demonstrated less herpetic infections. Prophylaxis should begin on the first day of each treatment phase and should be maintained throughout the course of treatment for at least for 1 month. It should be noted that acyclovir can cause several immunological phenomena including rash itself, which has to be differentiated from IARs and could be improved by the transition to a newer treatments, such as Valacyclovir, as an alternative.

In the approval trials infections were moderately increased in Alemtuzumab group compared with interferon group, represented mainly by mild to moderate infections in the upper respiratory tract, gastroenteritis and urinary tract infections [70]. This is a completely different profile compared to hematological patients treated by higher doses of Alemtuzumab demonstrating specific opportunistic infections of immunosuppression [71]. In MS patients, infections were not prolonged and receded under traditional medical therapy. Serious or opportunistic infections were not noticed to be increased. Pre-existing chronic diseases, such as tuberculosis, can be reactivated. No data are available regarding reactivation of controlled chronic $\mathrm{HBV} /$ $\mathrm{HCV}$ infections. In a recent observation period of 7 years no change in the malignancy rate has been detected [44]. As the thyroid is carefully investigated because of thyroid autoimmunity by eg. ultrasound, a rise in the incidence of thyroid papillary carcinoma diagnosis may be the consequence suggesting overdiagnosis [72].

\section{Autoimmune adverse events}

In a recent study for long-term safety evaluation an incidence of $48 \%$ for secondary autoimmune diseases was reported [44]. This is attributed to dysregulated B cells, resulting in secondary autoimmunity [17]. Because of this high incidence of secondary autoimmune diseases, determining biomarkers that can predict which patients are more susceptible to develop secondary autoimmunity is of high importance. Even though a high value of interleukin 21 at baseline could successfully predict the occurrence of autoimmune diseases in Alemtuzumab treated patients, it is inadvisable to rely on these values when taking the treatment decision, because of problems related to the confirmation of results by the currently available kits $[18,19]$. An overview about the lab testing as part of the risk monitoring plan is demonstrated in Fig. 4.

\section{Thyroid disease}

The development of autoimmune thyroid diseases is of high importance as it can be detected in more than $35 \%$ of patients treated with Alemtuzumab in the 4 years after first Alemtuzumab infusion [60]. Both hypo- and hyperthyroidism may occur, and the development of Graves' disease was highly prevalent [55].

The peak of incidence is reported to be in the third year after the first dose of Alemtuzumab. Most events are of mild to moderate severity and can respond to conventional therapies. However, surgical intervention may be needed in less than $1 \%$ of patients. The occurrence of thyroids side effects requires careful assessment of the clinical status of the patient and the necessity of medical and/or surgical therapies before continuing Alemtuzumab treatment. According to data derived from clinical studies, the baseline value of anti-TPO antibodies before starting alemtuzumab could not predict the development of thyroid side effects. Almost $80 \%$ of patients who manifested with thyroidal problems after alemtuzumab therapy, showed negative anti-TPO antibody status at the beginning of the study [60].

\section{Alemtuzumab-induced thrombocytopenia}

In addition, Alemtuzumab-induced autoimmune-mediated thrombocytopenia was reported in more than $1 \%$ of patients, which represents a form of idiopathic thrombocytopenia (ITP) $[26,58,73]$.

Acute ITP has occured in ab to $2 \%$ of the treated patients in clinical MS-studies within 14-36 months after the first exposure to alemtuzumab. ATP can manifest clinically with higher tendency to bruises, petechias, spontaneous mucosal bleedings (epistaxis, hemoptysis), severe or irregular menstrual bleeding or symptoms of anemia due to blood loss including serious hemodynamic complications. Complete blood count including platelet value should be performed monthly over at least 48 months after the last alemtuzumab infusion. The platelet control should be performed weekly in case that platelet count drops to less than $30 \%$ of its initial value or below the normal range, and hematological consultation should be ordered when the platelet number is less than $100.000 \mathrm{GPt} / \mathrm{l}$.

Normally the acute treatment of thrombocytopenia is usually low to high dose corticosteroids, it does not tend to develop a chronic condition. Reports about continuing alemtuzumab therapy after the development of ATP are limited and giving a new alemtuzumab infusion should be assessed on an individual basis [2].

\section{Nephropathies}

Nephropathies and individual cases of Goodpasture's syndrome with renal and pulmonary infection were reported 


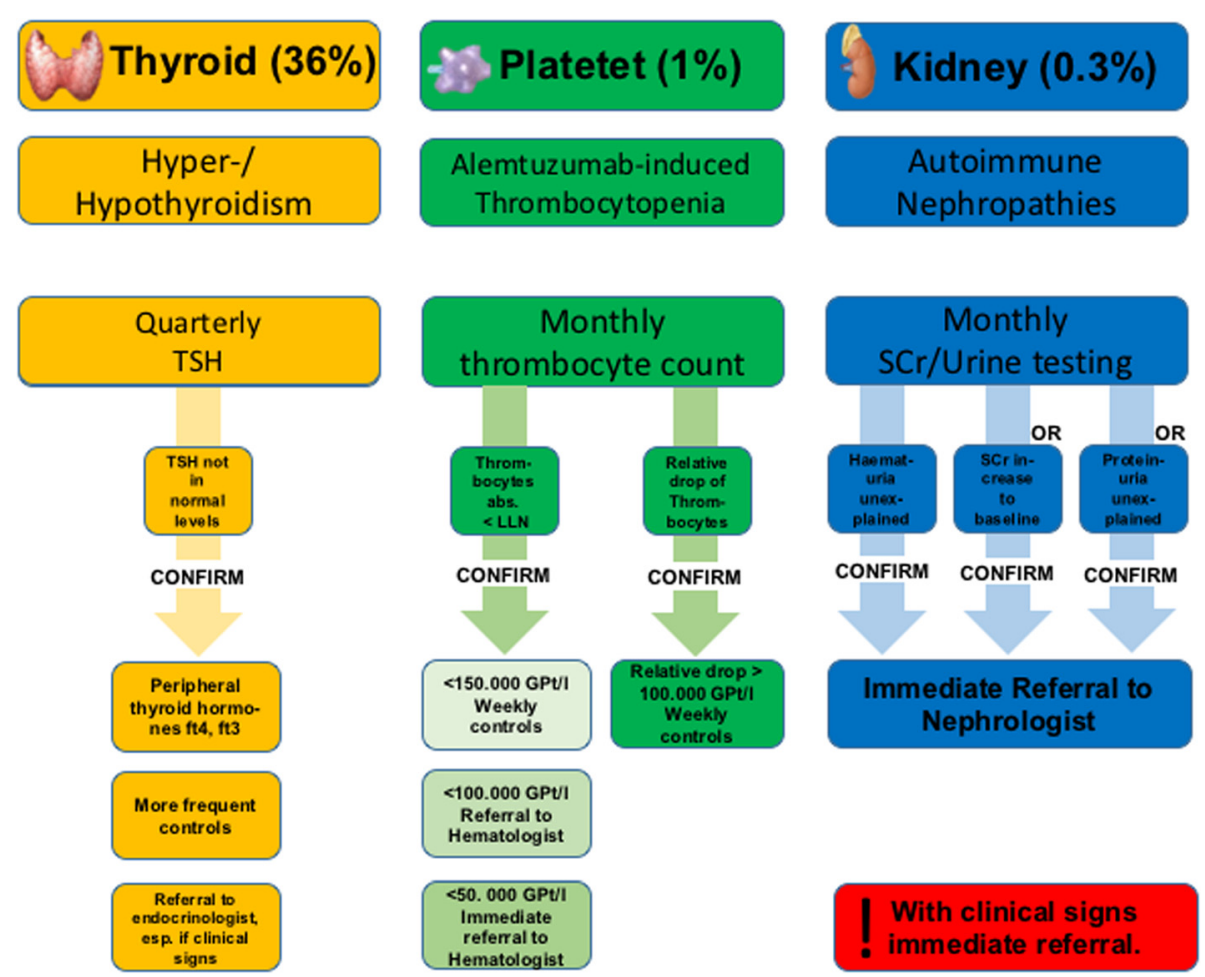

Fig. 4 Algorithm for monitoring patients after alemtuzumab infusion regarding secondary autoimmune side effects

in $0.3 \%$ of the patients $[44,74]$. Nephropathies including anti-glomerular basement membrane (anti-GBM) disease, occured in $0.3 \%$ of the patients in clinical MS-studies up to 39 months after the last administration of Alemtuzumab. These cases were early recognized by clinical and laboratory control, so that they could follow favorable course after effective treatment. The development of anti-glomerular basement membrane (anti-GBM) disease without suitable monitoring had led to renal failure, which in case of delayed treatment led to dialysis and/or kidney transplantation. Such side effects can be detected by laboratory monitoring through the presence of hematuria, proteinuria and/or creatinine elevation. Consequently, an urgent specialized nephrological consultation will be necessary.

\section{Vaccinations}

The efficacy of vaccines during and closely after Alemtuzumab application can be limited. That is why it is recommended to check the success of the vaccinations by determining their respective titers. The use of attenuated living vaccination should be avoided. Patients should fulfill the vaccination requirements at least six weeks before starting the Alemtuzumab therapy. It should be emphasized that for patients treated with Alemtuzumab the flu-vaccine should be delayed at least six months after the last infusion; however this vaccination can be repeated in case the first vaccination was not efficient.
One pilot study showed that for patients treated with Alemtuzumab the humoral immunological response after different vaccinations was not different from that detected in respective controls $[6,75]$, implying that the immune competence is restored after lymphocytes depletion induced by Alemtuzumab therapy. This is in line with the data derived from clinical studies which demonstrated low incidence of opportunistic infections following Alemtuzumab infusions. However this study was small and only 5 patients were vaccinated within the first 6 months after Alemtuzumab [16, 76, 77].

Moreover different studies suggested that the long lasting lymphopenia is neither associated with higher incidence of infections nor with higher activity of MS compared with accelerated lymphocyte reconstitution $[12,15,78]$.

\section{Pregnancy}

No safety data are available till now regarding the potential influence of Alemtuzumab on male fertility. The concerns regarding potential effect on fertility remains not well investigated, as the target antigen CD52 is also found in the tissues of the reproductive system.

Alemtuzumab is contraindicated during pregnancy and lactation, as animal studies have shown reproductive toxicity because Alemtuzumab, as well as human immunoglobulins, can cross the placenta. The same applies during lactation as they can be transferred by breast milk, and 
the risk to the infant is unknown. Additionally, the increased incidence of autoimmune diseases such as thyroid disease, particularly by the use of Alemtuzumab in women of childbearing age represents potential concern [79].

The development of autoimmune diseases had been observed during the study period within a maximum in the third year after first infusion followed by a decrease in risk [44]. So it makes sense to plan for pregnancy either after this period has passed or before the third year which means 4 months after the second infusion, and then profit from the prolonged high efficiency without the need for additional medication.

\section{Treatment following the 2 Alemtuzumab courses}

The majority of MS patients treated with Alemtuzumab do not need additional Alemtuzumab infusions or different MS treatments in the first 5 years after Alemtuzumab treatment. In a recent analysis for ECTRIMS 2015, $68 \%$ of CARE-MS1 and $60 \%$ of CARE-MS2 have not received additional Alemtuzumab infusions. $22.1 \%$ resp. $8.0 \%$ of CARE-MS1 and $28.8 \%$ resp. $9.9 \%$ of CAREMS2 patients have received one resp. two Alemtuzumab retreatments. In both clinical trials, the threshold for Alemtuzumab retreatment was quite low with one relapse activity or two new T2 lesions resp. one new Gd + lesion in the follow up MRI. If the treatment strategy of Alemtuzumab has been selected after careful consideration, this selected strategy should be generally maintained which means that retreatments should be applied at least once or twice if needed. Every retreatment should be accompanied with careful consideration about retreatment, disease activity, response to Alemtuzumab and additional treatment options. If the patient seems to be an Alemtuzumab-non-responder, alternative treatment strategies should be considered as eg. Fingolimod or B-cell depleting therapies.

In the clinical trials, $2.3 \%$ resp. $7.6 \%$ of the CARE-MS 1 resp. 2 patients have been treated with other MS treatments in the first 5 years after Alemtuzumab start. The majority of these 96 out of 1496 patients used baseline medication (interferon and GA), $10 \%$ each were treated with Fingolimod and Natalizumab. Switching after Alemtuzumab to Interferon-beta or Glatiramer Acetate can be done quite quickly after the last Alemtuzumab infusion after excluding relevant lymphopenia especially for interferon treatment. There is not a lot of experience with the new oral medications Teriflunomide and Dimethylfumarate. Especially with Dimethylfurmarate, the previous immunosuppression with Alemtuzumab has to be considered. By switching to Natalizumab it should be kept in mind that Alemtuzumab leads to significant long-lasting changes in the adaptive immunity cells. As Alemtuzumab works as an immunosuppressive, changing to Natalizumab is associated with higher risk for PML development especially in patients with positive JCV antibodies. The better treatment option of highly active MS treatments which has already been used in our center is Fingolimod. Because of the individually very different prolonged effect of Alemtuzumab on the adaptive immunity, it is not possible to give a general waiting period after the last Alemtuzumab infusion. A complete immune status can be helpful including differential blood count, CD4+ T cells, CD8+ T cells, B cells, NK cells.

\section{Conclusions}

Alemtuzumab is a highly efficacious disease-modifying therapy which offers a new treatment principle for the treatment of relapsing-remitting MS. It shows clear benefits on relapses, disability outcomes, and freedom from clinical disease and magnetic resonance imaging activity. Infusion-associated reactions are common with Alemtuzumab, but rarely serious. Infection incidence was elevated with Alemtuzumab in clinical studies; most infections were mild or moderate in severity. Autoimmune adverse events occurred in approximately a third of patients, manifesting mainly as thyroid disorders, and less frequently as immune thrombocytopenia or nephropathy. A comprehensive monitoring program lasting at least 4 years after the last alemtuzumab dose allows early detection and effective management of autoimmune adverse events. Further experience with alemtuzumab in the clinic will provide needed long-term data.

\section{Authors' contributions}

$\mathrm{LH}$ and TZ designed and drafted the manuscript. JE and $\mathrm{KT}$ added important contact. All authors read and approved the final manuscript.

\section{Competing interests}

Tjalf Ziemssen has received reimbursements for participation in scientific advisory boards from Bayer Healthcare, Biogen Idec, Novartis Pharma AG, Merck Serono, Teva, Genzyme, and Synthon. He has also received speaker honorarium from Bayer Healthcare, Biogen Idec, Genzyme, Merck Sharp \& Dohme, GlaxoSmithKline, Novartis Pharma AG, Teva, Sanofi Aventis, and Almirall. He has also received research support from Bayer Healthcare, Biogen Idec, Genzyme, Novartis Pharma AG, Teva, and Sanofi Aventis. Katja Thomas received honorarium from Novartis and Bayer. Lina Hassoun and Judith Eisele have no disclosures.

Received: 11 January 2016 Accepted: 24 May 2016

Published online: 02 August 2016

\section{References}

1. Coles A, Deans J, Compston A. Campath-1H treatment of multiple sclerosis: lessons from the bedside for the bench. Clin Neurol Neurosurg. 2004;106:270-4.

2. Kousin-Ezewu O, Coles A. Alemtuzumab in multiple sclerosis: latest evidence and clinical prospects. Ther Adv Chronic Dis. 2013;4:97-103.

3. Cox AL, Thompson SAJ, Jones JL, Robertson VH, Hale G, Waldmann H, et al. Lymphocyte homeostasis following therapeutic lymphocyte depletion in multiple sclerosis. Eur J Immunol. 2005;35:3332-42.

4. Cohen JA, Coles AJ, Arnold DL, Confavreux C, Fox EJ, Hartung H-P, et al. Alemtuzumab versus interferon beta 1a as first-line treatment for patients with relapsing-remitting multiple sclerosis: a randomised controlled phase 3 trial. 2012.

5. CAMMS223 Trial Investigators, Coles AJ, Compston DAS, Selmaj KW, Lake SL, Moran S, et al. Alemtuzumab vs. interferon beta-1a in early multiple sclerosis. N Engl J Med. 2008;359:1786-801.

6. Coles AJ, Twyman CL, Arnold DL, Cohen JA, Confavreux C, Fox EJ, et al. Alemtuzumab for patients with relapsing multiple sclerosis after diseasemodifying therapy: a randomised controlled phase 3 trial. 2012. 
7. Watanabe T, Masuyama J-I, Sohma Y, Inazawa H, Horie K, Kojima K, et al. CD52 is a novel costimulatory molecule for induction of CD4+ regulatory T cells. Clin Immunol. 2006;120:247-59.

8. Xia MQ, Tone M, Packman L, Hale G, Waldmann H. Characterization of the CAMPATH-1 (CDw52) antigen: biochemical analysis and CDNA cloning reveal an unusually small peptide backbone. Eur J Immunol. 1991;21:1677-84.

9. Thomas K, Eisele JC, Rodriguez-Leal FA, Hainke U, Ziemssen T. Acute effects of alemtuzumab infusion in active relapsing remitting multiple sclerosis patients. Neurology: Neuroimmunology \& Neuroinflammation. 2016;3, e228.

10. Willis MD, Harding KE, Pickersgill TP, Wardle M, Pearson OR, Scolding NJ, et al. Alemtuzumab for multiple sclerosis: Long term follow-up in a multicentre cohort. Mult Scler. 2015.

11. Coles AJ, Cox A, Le Page E, Jones J, Trip SA, Deans J, et al. The window of therapeutic opportunity in multiple sclerosis: evidence from monoclonal antibody therapy. J Neurol. 2006;253:98-108.

12. Cossburn MD, Harding K, Ingram G, El-Shanawany T, Heaps A, Pickersgill TP, et al. Clinical relevance of differential lymphocyte recovery after alemtuzumab therapy for multiple sclerosis. Neurology. 2012;80:55-61.

13. Freedman MS, Kaplan JM, Markovic-Plese S. Insights into the Mechanisms of the Therapeutic Efficacy of Alemtuzumab in Multiple Sclerosis. J Clin Cell Immunol. 2013:4.

14. Hu Y, Turner MJ, Shields J, Gale MS, Hutto E, Roberts BL, et al. Investigation of the mechanism of action of alemtuzumab in a human CD52 transgenic mouse model. Immunology. 2009;128:260-70.

15. Kousin-Ezewu O, Parker RA, Tuohy O, Compston A, Coles A, Jones J. Accelerated lymphocyte recovery after alemtuzumab does not predict multiple sclerosis activity. Neurology. 2014;82:2158-64.

16. Hill-Cawthorne GA, Button T, Tuohy O, Jones JL, May K, Somerfield J, et al. Long term lymphocyte reconstitution after alemtuzumab treatment of multiple sclerosis. J Neurol Neurosurg Psychiatr. 2012;83:298-304.

17. Cossburn M, Pace AA, Jones J, Ali R, Ingram G, Baker K, et al. Autoimmune disease after alemtuzumab treatment for multiple sclerosis in a multicenter cohort. Neurology. 2011;77:573-9.

18. Jones JL, Phuah C-L, Cox AL, Thompson SA, Ban M, Shawcross J, et al. IL-21 drives secondary autoimmunity in patients with multiple sclerosis, following therapeutic lymphocyte depletion with alemtuzumab (Campath-1H). J Clin Invest. 2009;119:2052-61.

19. Harding KE, Cossburn M, Robertson N, Compston A, Coles AJ, Jones JL. Predicting autoimmunity after alemtuzumab treatment of multiple sclerosis. J Neurol Neurosurg Psychiatr. 2014;85:795-8.

20. Sørensen PS, Koch-Henriksen N, Petersen T, Ravnborg M, Oturai A, Sellebjerg F. Recurrence or rebound of clinical relapses after discontinuation of natalizumab therapy in highly active MS patients. J Neurol. 2014;261:1-8.

21. Vellinga MM, Castelijns JA, Barkhof F, Uitdehaag BMJ, Polman CH. Postwithdrawal rebound increase in T2 lesional activity in natalizumabtreated MS patients. Neurology. 2008;70:1150-1.

22. La Mantia L, Prone V, Marazzi MR, Erminio C, Protti A. Multiple sclerosis rebound after fingolimod discontinuation for lymphopenia. Neurol Sci. 2014;35:1485-6.

23. Havla JB, Pellkofer HL, Meinl I, Gerdes LA, Hohlfeld R, Kümpfel T. Rebound of disease activity after withdrawal of fingolimod (FTY720) treatment. Arch Neurol. 2012;69:262-4

24. Piscolla E, Hakiki B, Pasto L, Razzolini L, Portaccio E, Amato MP. Rebound after Fingolimod suspension in a pediatric-onset multiple sclerosis patient. J Neurol. 2013;260:1675-7.

25. Sempere AP, Berenguer-Ruiz L, Feliu-Rey E. Rebound of disease activity during pregnancy after withdrawal of fingolimod. Eur J Neurol. 2013:20:e109-10.

26. Havrdova E, Horakova D, Kovarova I. Alemtuzumab in the treatment of multiple sclerosis: key clinical trial results and considerations for use. Ther Adv Neurol Disord. 2015;8:31-45.

27. Weber MS, Menge T, Lehmann-Horn K, Kronsbein HC, Zettl U, Sellner J, et al. Current treatment strategies for multiple sclerosis-efficacy versus neurological adverse effects. Curr Pharm Des. 2012;18:209-19.

28. Plavina T, Subramanyam M, Bloomgren G, Richman S, Pace A, Lee S, et al. Anti-JCV antibody levels in serum or plasma further define risk of natalizumab-associated PML. Ann Neurol. 2014;76:802-12.

29. Fenu G, Lorefice L, Frau F, Coghe GC, Marrosu MG, Cocco E. Induction and escalation therapies in multiple sclerosis. Antiinflamm Antiallergy Agents Med Chem. 2015;14:26-34

30. Bayas A, Baum K, Bitsch A, Haas J, Hellwig K, Lang M, et al. One Year Alemtuzumab - What have we Learned in Clinical Practice? Exchange of
Experience between Experts on Treatment of Multiple Sclerosis. Akt Neurol. 2015; 42(09):535-41.

31. Lublin FD, Reingold SC, Cohen JA, Cutter GR, Sørensen PS, Thompson AJ, et al. Defining the clinical course of multiple sclerosis: the 2013 revisions. Neurology. 2014;83:278-86.

32. Bermel RA, Naismith RT. Using MRI to make informed clinical decisions in multiple sclerosis care. Curr Opin Neurol. 2015;28:244-9.

33. Ziemssen $T$, De Stefano N, Pia Sormani M, Van Wijmeersch B, Wiendl $\mathrm{H}$, Kieseier BC. Optimizing therapy early in multiple sclerosis: An evidence-based view. Multiple Sclerosis and Related Disorders. 2015:4:460-9.

34. Ziemssen T, Derfuss T, Stefano N, Giovannoni G, Palavra F, Tomic D, et al. Optimizing treatment success in multiple sclerosis. J Neurol. Springer Berlin Heidelberg; 2015;1-15

35. Coles AJ, Wing M, Smith S, Coraddu F, Greer S, Taylor C, et al. Pulsed monoclonal antibody treatment and autoimmune thyroid disease in multiple sclerosis. Lancet. 1999;354:1691-5.

36. Leray E, Yaouanq J, Le Page E, Coustans M, Laplaud D, Oger J, et al. Evidence for a two-stage disability progression in multiple sclerosis. Brain. 2010;133:1900-13.

37. Le Page E, Deburghgraeve V, Lester M-A, Cardiet I, Leray E, Edan G. Alemtuzumab as rescue therapy in a cohort of 16 aggressive multiple sclerosis patients previously treated by Mitoxantrone: an observational study. J Neurol. 2015;262:1024-34.

38. Rothenbacher D, Capkun G, Uenal H, Tumani H, Geissbühler Y, Tilson H. New opportunities of real-world data from clinical routine settings in lifecycle management of drugs: example of an integrative approach in multiple sclerosis. Curr Med Res Opin. 2015;31:953-65.

39. Garnock-Jones KP. Alemtuzumab: a review of its use in patients with relapsing multiple sclerosis. Drugs. 2014;74:489-504.

40. Gelfand JM, Cotter J, Klingman J, Huang EJ, Cree BAC. Massive CNS monocytic infiltration at autopsy in an alemtuzumab-treated patient with NMO. Neurology: Neuroimmunology \& Neuroinflammation. 2014;1:e34-4.

41. Azzopardi L, Cox AL, McCarthy CL, Jones JL, Coles AJ. Alemtuzumab use in neuromyelitis optica spectrum disorders: a brief case series. J Neurol. 2015;263:1-5.

42. Fujihara K, Nakashima I. Secondary progression and innate immunity in NMO: A possible link to alemtuzumab therapy? Neurology: Neuroimmunology \& Neuroinflammation. 2014;1:e38-8.

43. Nali LHDS, Moraes L, Fink MCD, Callegaro D, Romano CM, Oliveira ACP D. Natalizumab treatment for multiple sclerosis: updates and considerations for safer treatment in JCV positive patients. Arq Neuropsiquiatr. 2014;0:0.

44. Tuohy O, Costelloe L, Bjornson I, Harding K, Robertson N, May K, et al. Alemtuzumab treatment of multiple sclerosis: long-term safety and efficacy. J Neurol Neurosurg Psychiatr. 2014;0:1-8.

45. Thomas K, Ziemssen T. Management of fingolimod in clinical practice. Clin Neurol Neurosurg. 2013;115(1):S60-4.

46. Berger JR, Centonze D, Comi G, Confavreux C, Cutter G, Giovannoni G, et al Considerations on discontinuing natalizumab for the treatment of multiple sclerosis. Ann Neurol. 2010;68:409-11.

47. Hauser SL, Johnston SC. Balancing risk and reward: the question of natalizumab. Ann Neurol. 2009;66:A7-8.

48. Ziemssen $\mathrm{T}$, Hillert J, Butzkueven $\mathrm{H}$. The importance of collecting structured clinical information on multiple sclerosis. BMC Med. 2016;14:81.

49. Diel R, Hauer B, Loddenkemper R, Manger B, Krüger K. Recommendations for tuberculosis screening before initiation of TNF-alpha-inhibitor treatment in rheumatic diseases. Pneumologie. 2009;63:329-34.

50. Caon C, Namey M, Meyer C, Mayer L, Oyuela P, Margolin DH, et al. Prevention and Management of Infusion-Associated Reactions in the Comparison of Alemtuzumab and Rebif ${ }^{\oplus}$ Efficacy in Multiple Sclerosis (CARE-MS) Program. Int J MS Care. 2015;17:191-8.

51. Moreau T, Coles A, Wing M, Isaacs J, Hale G, Waldmann H, et al. Transient increase in symptoms associated with cytokine release in patients with multiple sclerosis. Brain. 1996;119(Pt 1):225-37.

52. Wing MG, Moreau T, Greenwood J, Smith RM, Hale G, Isaacs J, et al. Mechanism of first-dose cytokine-release syndrome by CAMPATH 1-H: involvement of CD16 (FcgammaRIII) and CD11a/CD18 (LFA-1) on NK cells. J Clin Invest American Society for Clinical Investigation. 1996;98:2819-26.

53. Rebello P, Hale G. Pharmacokinetics of CAMPATH-1H: assay development and validation. J Immunol Methods. 2002;260:285-302. 
54. Klotz L, Berthele A, Bruck W, Chan A, Flachenecker P, Gold R, et al. Monitoring of blood parameters under course-modified MS therapy: Substance-specific relevance and current recommendations for action. Nervenarzt: Springer Berlin Heidelberg; 2016. p. 1-14

55. Tsourdi E, Gruber M, Rauner M, Blankenburg J, Ziemssen T, Hofbauer LC. Graves' disease after treatment with Alemtuzumab for multiple sclerosis. Hormones (Athens). 2015;14(1):148-53.

56. Williams KM, Dietzen D, Hassoun AA, Fennoy I, Bhatia M. Autoimmune thyroid disease following alemtuzumab therapy and hematopoietic cell transplantation in pediatric patients with sickle cell disease. Pediatr Blood Cancer. 2014;61(12):2307-9.

57. Aranha AA, Amer S, Reda ES, Broadley SA, Davoren PM. Autoimmune Thyroid Disease in the Use of Alemtuzumab for Multiple Sclerosis: A Review. Endocr Pract. 2013;11:1-25

58. Cuker A, Coles AJ, Sullivan H, Fox E, Goldberg M, Oyuela P, et al. A distinctive form of immune thrombocytopenia in a phase 2 study of alemtuzumab for the treatment of relapsing-remitting multiple sclerosis. Blood. 2011;118:6299-305.

59. Jones UL, Coles AJ. Mode of action and clinical studies with alemtuzumab. Exp Neurol. 2014;262:37-43.

60. Daniels GH, Vladic A, Brinar V, Zavalishin I, Valente W, Oyuela P, et al. Alemtuzumab-Related Thyroid Dysfunction in a Phase 2 Trial of Patients With Relapsing-Remitting Multiple Sclerosis. J Clin Endocrinol Metab. 2014;99:80-9.

61. Haase R, Schultheiss T, Kempcke R, Thomas K, Ziemssen T. Use and acceptance of electronic communication by patients with multiple sclerosis: a multicenter questionnaire study. J Med Internet Res. 2012;14, e135.

62. Ziemssen T, Engelmann U, Jahn S, Leptich A, Kern R, Hassoun L, et al. Rationale, Design, and Methods of a Non-interventional Study to Establish Safety, Effectiveness, Quality of Life, Cognition, Health-Related and Work Capacity Data on Alemtuzumab in Multiple Sclerosis Patients in Germany (TREAT-MS). BMC Neurol. 2016. in press.

63. Ziemssen $T$, Kern $R$, Cornelissen $C$. The PANGAEA study design-a prospective, multicenter, non-interventional, long-term study on fingolimod for the treatment of multiple sclerosis in daily practice. BMC Neurol BMC Neurology. 2015;18:1-8.

64. Ziemssen T, Kempcke R, Eulitz M, Großmann L, Suhrbier A, Thomas K, et al. Multiple sclerosis documentation system (MSDS): moving from documentation to management of MS patients. J Neural Transm. 2013;120 Suppl 1:61-6.

65. Rieckmann P, Boyko A, Centonze D, Elovaara I, Giovannoni G, Havrdova E, et al. Achieving patient engagement in multiple sclerosis_ A perspective from the multiple sclerosis in the 21 st Century Steering Group. Multiple Sclerosis and Related Disorders. 2015;4:202-18.

66. Schultheiß T, Kempcke R, Kratzsch F, Eulitz M, Pette M, Reichmann H, et al. Multiple sclerosis management system 3D: Moving from documentation towards management of patients. Nervenarzt: Springer Berlin Heidelberg; 2011.

67. Rau D, Lang M, Harth A, Naumann M, Weber F, Tumani H, et al. Listeria Meningitis Complicating Alemtuzumab Treatment in Multiple SclerosisReport of Two Cases. IJMS. 2015;16:14669-76.

68. Thomas K, Dietze K, Wehner R, Metz I, Tumani H, Schultheiss T, et al, Accumulation and therapeutic modulation of 6-sulfo LacNAC (+) dendritic cells in multiple sclerosis. Neurology: Neuroimmunology \& Neuroinflammation. 2014;1:e33-3.

69. Morrison VA. Immunosuppression associated with novel chemotherapy agents and monoclonal antibodies. Clin Infect Dis. 2014;59(5):S360-4.

70. Coles AJ. Alemtuzumab therapy for multiple sclerosis. Neurotherapeutics. 2013;10:29-33

71. Safdar N, Smith J, Knasinski V, Sherkow C, Herrforth C, Knechtle S, et al. Infections after the use of alemtuzumab in solid organ transplant recipients: a comparative study. Diagn Microbiol Infect Dis. 2010;66:7-15.

72. Ibitoye R, Wilkins A. Thyroid papillary carcinoma after alemtuzumab therapy for MS. J Neurol. 2014;261(9):1828-9.

73. Brown W, Coles A. Alemtuzumab: evidence for its potential in relapsing\&ndash remitting multiple sclerosis. Drug Des Devel Ther. 2013;7:131.

74. Coles AJ, Fox E, Vladic A, Gazda SK, Brinar V, Selmaj KW, et al. Alemtuzumab more effective than interferon-1a at 5-year follow-up of CAMMS223 Clinical Trial. Neurology. 2012;78:1069-78.

75. McCarthy CL, Tuohy O, Compston DAS, Kumararatne DS, Coles AJ, Jones JL. Immune competence after alemtuzumab treatment of multiple sclerosis. Neurology. 2013;81:872-6.

76. Zhang X, Tao Y, Chopra M, Ahn M, Marcus KL, Choudhary N, et al. Differential Reconstitution of $\mathrm{T}$ Cell Subsets following Immunodepleting
Treatment with Alemtuzumab (Anti-CD52 Monoclonal Antibody) in Patients with Relapsing-Remitting Multiple Sclerosis. J Immunol. 2013; 191:5867-74.

77. Robertson NP, Scolding NJ. Immune reconstitution and treatment response in multiple sclerosis following alemtuzumab. Neurology. 2014;82:2150-1.

78. Tchao NK, Turka LA. Lymphodepletion and homeostatic proliferation: implications for transplantation. Am J Transplant. 2012;12:1079-90.

79. Vukusic S, Marignier R. Multiple sclerosis and pregnancy in the 'treatment era'. Nat Rev Neurol. 2015;11:280-9.

\section{Submit your next manuscript to BioMed Central and we will help you at every step:}

- We accept pre-submission inquiries

- Our selector tool helps you to find the most relevant journal

- We provide round the clock customer support

- Convenient online submission

- Thorough peer review

- Inclusion in PubMed and all major indexing services

- Maximum visibility for your research

Submit your manuscript at www.biomedcentral.com/submit 